\title{
ANALISIS BUKU MATEMATIKA KURIKULUM 1975 DAN KURIKULUM 2013
}

\author{
Muhammad Taqiyuddin ${ }^{1)}$, Faliqul Jannah Firdausi ${ }^{2)}$ \\ 1) MTs Darul Ulum, Jl. Kromodiwiryo Ds. Purwogondo Kec. Kalinyamatan, Kab. Jepara; \\ taqi94@hotmail.com \\ 2) SMA Negeri 15 Bandung, Jl. Sarimanis I Kel. Sarijadi Kec. Sukasari, Kota Bandung; \\ faliqul.firdausi@gmail.com
}

\begin{abstract}
Abstrak. Penelitian ini mengkaji buku-buku matematika Indonesia yang menggunakan kurikulum 1975 dan kurikulum 2013. Kajian yang penulis paparkan mencakup karakteristik fisik, proses pengembangan, perincian topik dan karakteristik isi buku. Dalam hal metodologi, penulis menggunakan content analysis dalam proses analisisnya. Berdasar analisis yang telah penulis lakukan, terdapat beberapa yang patut diapresiasi dari buku-buku kurikulum 2013, misalnya, bagaimana sebuah konsep Matematika dijelaskan dalam buku dengan menggunakan beberapa pendekatan, bervariasinya rujukan buku, perincian profil penulis, dan contoh soal yang variatif. Meskipun demikian, terdapat beberapa hal yang perlu terus diperbaiki secara berkelanjutan seperti uji coba yang matang, penyesuaian kegiatan siswa yang dicantumkan di buku, ilustrasi riil dan data nyata. Lebih lanjut, penulis juga mengajak semua pihak agar buku Matematika Indonesia di masa yang akan datang terus dapat mengikuti dan memanfaatkan kecanggihan teknologi terkini.
\end{abstract}

Kata Kunci. Kurikulum 1975; Kurikulum 2013; Telaah Buku Matematika.

\section{An Analysis of Curriculum 1975 and Curriculum 2013 Mathematics Textbook}

\begin{abstract}
This study examines Indonesian mathematics textbooks written based on the 1975 curriculum and the 2013 curriculum. This study analyses the physical characteristics, development process, topics breakdown, and contents characteristics of the textbooks. In analyzing the data, the researchers applied content analysis method. Based on the analysis results, it can be inferred that there are some aspects in the 2013 curriculum textbooks should be appreciated, for example, how a Mathematical concept is explained by applying several approaches, varied book references, details of the writer's profile, and examples of varied problems. Nonetheless, there are a number of things need to be continually improved such as the well-prepared trial testing, students' activities adjustments listed in the textbooks, appropriate and real illustrations. Furthermore, the writers invite all parties to make such eforts that Indonesian Mathematics textbooks in the future may adjust and leverage the latest technological updates.
\end{abstract}

Keyword. 1975 Curriculum, 2013 Curriculum, Analysis of Mathematics Textbook.

\section{Pendahuluan}

Pengembangan buku Matematika merupakan salah satu elemen krusial dari pergerakan revolusi pendidikan Matematika menuju ke arah yang lebih baik, maju, dan modern. Peranan penting keberadaan buku mata pelajaran dalam proses pembelajaran merupakan hal yang 
utama. Misalnya, isi buku Matematika berpengaruh terhadap materi apa saja yang dibahas dalam pembelajaran di kelas dan bagaimana materi tersebut diajarkan (Thompson, Senk, \& Johnson, 2012; Valverde, et al., 2002). Hal ini terjadi karena guru Matematika sangat bergantung kepada buku mata pelajaran dalam proses mendesain pembelajaran yang akan dilaksanakan di kelas (Beaton et al., 1996; Sun, Kulm, \& Capraro, 2009). Dari sudut pandang siswa, buku Matematika adalah salah satu sumber yang memberikan kesempatan untuk mempelajari sebuah topik dan atau aspek tertentu dari Matematika atau yang sering disebut sebagai “opportunity to learn" (OTL) (Wijaya, Van den Heuvel-Panhuizen, \& Doorman, 2015; Fan, 2013). Lebih lanjut, Hadar (2017, hlm. 161) mengungkapkan bahwa perolehan nilai matematika siswa pada ujian nasional di beberapa negara dipengaruhi oleh pemilihan buku yang digunakan dalam proses belajar mengajar di kelas. Dengan memandang pentingnya upaya memajukan kualitas matematika di Indonesia, penelitian yang mengkaji buku mata pelajaran Matematika perlu terus ditingkatkan.

Melihat Indonesia dari kacamata Internasional dalam diskursus ini juga penting karena akan menjadikan Indonesia introspeksi akan posisinya terhadap negara lain dalam hal penelitian buku mata pelajaran. Dari beberapa jurnal internasional Pendidikan Matematika, akan tampak bahwa sudah banyak penelitian yang mengkaji buku-buku Matematika dari Amerika Serikat, Swedia, dan Tiongkok (Thompson, Senk, \& Johnson, 2012; Van Steenbrugge, \& Ryve, 2018; $\mathrm{Xu}, 2013)$. Di lain pihak, hanya ada beberapa penelitian yang sudah dilakukan di Indonesia yang menelaah aspek tertentu dari buku mata pelajaran. Sebagai contoh, Wijaya et al (2015) telah mengkaji soal-soal pada buku Matematika Indonesia kelas delapan dan menginvestigasi bagaimana OTL untuk mempelajari permasalahan berbasis kontekstual. Artinya, masih banyak aspek lain yang masih perlu mendapat perhatian dari peneliti.

Penelitian tentang isi dan penyajian buku mata pelajaran matematika di Indonesia berdasarkan kurikulum 1975 dan kurikulum 2013 ini sangat penting untuk mengevaluasi isi dan penyajian buku-buku tersebut. Kurikulum 1975 dipilih karena merupakan salah satu kurikulum pertama setelah Indonesia merdeka pada 1945. Meskipun ada kurikulum yang berlaku di antara 1945 dan 1975, sering kali masa ini disebut sebagai kurikulum sebelum 1975 (lih. Zulkardi, 2002, hlm. 6; Mailizar, Alafaleq, \& Fan, 2014, hlm. 59) yang mengindikasikan tahun tersebut merupakan tahun spesial. Di lain pihak, kurikulum 2013 adalah kurikulum yang saat penelitian ini sedang berlangsung digunakan di Indonesia, 38 tahun setelah kurikulum 1975 pertama kali diterapkan. Penulis berharap dengan melakukan studi pada dua masa ini, akan tampak jelas bagaimana dulu Indonesia mengembangkan buku Matematika SMP kurikulum 1975, dan bagaimana Indonesia melakukannya hampir empat dasawarsa setelahnya.

Berdasarkan uraian di atas, penulis merumuskan beberapa permasalahan yang akan dikaji dalam penelitian ini, sebagai berikut.

1) Apa saja karakteristik fisik buku Matematika SMP kurikulum 1975 dan kurikulum 2013 ?

2) Siapa saja yang terlibat dalam proses penyusunan buku Matematika SMP kurikulum 1975 dan kurikulum 2013?

3) Bagaimana proses pengembangan buku Matematika SMP kurikulum 1975 dan kurikulum 2013?

4) Apa saja topik yang dipelajari pada buku Matematika SMP kurikulum 1975 dan kurikulum 2013?

5) Bagaimana buku Matematika SMP kurikulum 1975 dan kurikulum 2013 menjelaskan suatu konsep matematika?

6) Perbaikan apa saja yang dapat dilakukan untuk kemajuan isi dan penyajian buku Matematika SMP Indonesia di masa yang akan datang? 


\section{Metode Penelitian}

\subsection{Analisis Buku}

Studi ini menggunakan dua macam analisis yakni horizontal analysis dan vertical analysis yang dikembangkan oleh Caharalambous, et al (2010). Horizontal analysis terkait dengan fitur-fitur yang ada dalam buku Matematika, seperti banyak halaman dalam buku, topik-topik yang dituangkan dalam buku, dan urutan dari topik-topik tersebut. Di sisi lain, vertical analysis lebih terfokus dan secara mendalam menganalisis konten matematika yang ada di dalam buku. Konten-konten yang dianalisis adalah definisi, teorema, contoh soal dan jawabannya, serta soal-soal latihan.

\subsection{Kerangka Analisis}

Berdasarkan empat rumusan masalah, dibuatlah sebuah kerangka untuk mempermudah proses analisis dan sebagai acuan untuk menyajikan pembahasan hasil penelitian. Rincian kerangka ini dapat dilihat pada Tabel 1 . Selanjutnya, sumber data dalam penelitian ini menggunakan data primer yakni buku teks pelajaran (Heck, 2004, hlm. 237). Sementara itu, data sekunder pada penelitian ini meliputi dokumen penelitian tentang sejarah pendidikan matematika di Indonesia, disertasi yang membahas sejarah kurikulum pendidikan matematika Indonesia, dan dokumen laporan telaah kurikulum dan buku teks pelajaran (Hadi, 2002; Fauzan, 2002; Mailizar, Alafaleq, \& Fan, 2014; ACDP, 2017; Brodie, 1976).

Tabel 1. Kerangka Analisis Buku

\begin{tabular}{|c|c|}
\hline $\begin{array}{l}\text { Rumusan } \\
\text { Masalah }\end{array}$ & Aspek yang dianalisis \\
\hline 1 & Banyak buku yang disediakan untuk siswa SMP \\
\hline 2 & $\begin{array}{l}\text { Siapa saja penyusun buku } \\
\text { Siapa saja penelaah buku }\end{array}$ \\
\hline 3 & Tahapan-tahapan proses penyusunan buku \\
\hline 4 & Perincian topik yang dipelajari \\
\hline 5 & $\begin{array}{l}\text { Karakteristik narasi untuk menjelaskan suatu topik } \\
\text { Karakteristik ilustrasi atau gambar } \\
\text { Karakteristik soal }\end{array}$ \\
\hline 6 & $\begin{array}{l}\text { Hal yang dapat dipelajari dan diperbaiki untuk pengembangan buku } \\
\text { Matematika SMP masa depan }\end{array}$ \\
\hline
\end{tabular}

\section{Hasil dan Pembahasan}

Bahasan selanjutnya akan penulis sajikan dalam tiga bagian yakni terkait buku matematika kurikulum 1975, dilanjutkan dengan buku matematika kurikulum 2013, dan diakhiri dengan diskusi apa saja yang dapat diperbaiki dari buku Matematika SMP.

\subsection{Buku Matematika SMP Kurikulum 1975}

Terdapat enam jilid buku yang telah penulis telaah. Setiap buku digunakan dalam setengah tahun (per semester), seperti pada buku yang disadur untuk buku-buku tersebut (Brodie, 1976). Ini artinya buku satu untuk kelas tujuh semester satu, buku dua untuk kelas tujuh semester dua, dan seterusnya. Tahun terbit dari setiap jilid bervariasi dari tahun 1977, 1979, dan 1981. Meskipun berbeda-beda tahun terbitnya, penulis menemukan bahwa orang-orang yang terlibat dalam penyusunan buku ini semuanya sama. Pihak yang terlibat dalam penyusunan buku 
Matematika SMP kurikulum 1975 merupakan pakar Matematika terkemuka. Hal ini adalah pilihan yang tepat, karena dapat memastikan bahwa materi Matematika yang termuat dalam buku akan terjamin kualitasnya dari segi konsep Matematika. Meskipun demikian, ada baiknya pada proses ini, guru dan praktisi pendidikan, yang memiliki pengalaman berinteraksi dengan siswa secara intensif turut dilibatkan. Salah satu tujuannya adalah untuk menjamin materi yang terdapat pada buku mudah dipahami oleh siswa dan mudah digunakan oleh guru untuk panduan mengajar.

Semua buku kurikulum 1975 merupakan saduran dari buku Modern Mathematics for Schools (MMS) yang disusun oleh Scottish Mathematics Group. Buku tersebut dipilih karena terbukti baik dan telah disadur atau diterjemahkan di pelbagai negara, misalnya Singapura, Belanda, Norwegia pada masa itu (Brodie, 1976). Hal ini didukung oleh beberapa ulasan buku juga mengonfirmasi kualitas MMS karena salah satunya memuat penjelasan materi yang jelas dan akurat (Williams, 1973). Indonesia, tidak meniru secara utuh apa yang ada pada buku MMS. Buku MMS memuat bukan hanya buku siswa, namun juga buku guru dan progress paper (Holmes, 1975). Buku guru memuat petunjuk bagi guru dalam melaksanakan pembelajaran, sedangkan buku progress paper memuat latihan-latihan soal pilihan ganda. Meskipun demikian, dalam kata pengantar di setiap buku terdapat satu paragraf yang menjelaskan bagaimana seharusnya guru menggunakan materi dari buku.

Awalnya, hasil saduran ini diimplementasikan di beberapa kota di Indonesia yakni Daerah Khusus Ibukota Jakarta, Daerah Istimewa Yogyakarta, dan Kotamadya Surabaya. Tidak semua buku diujicobakan pada tahap awal ini, hanya Jilid 1, Jilid 2, dan Jilid 3 saja. Berdasarkan hasil implementasi yang telah dilaksanakan, penyusun buku mengklaim bahwa buku-buku tersebut cocok digunakan di Indonesia. Buku ini kemudian diproduksi, yang pada mulanya hanya untuk sekolah-sekolah negeri dan kemudian secara komersil disediakan untuk sekolah swasta.

Fenomena penyadur buku MMS ini sesuai dengan apa yang dikatakan oleh Hadi (2002) bahwa kurikulum Indonesia selalu mengikuti tren yang diikuti banyak negara di dunia. Kurikulum 1975 mengadopsi Modern Mathematics atau New Math (Fauzan, 2002; Sembiring, Hadi, \& Dolk, 2008) yang pada sekitar pertengahan 1950 sampai pertengahan 1970 diimplementasikan dalam pembelajaran matematika di banyak negara (Kilpatrick, 2012). Gerakan Modern Mathematics ini memiliki semangat untuk membawa Matematika yang dipelajari di sekolah mendekat kepada Matematika yang dipahami oleh para matematikawan pada saat itu. Salah satu cirinya adalah konten Matematika diusahakan agar teliti (Brodie, 1976). Artinya, setiap konsep yang disajikan dalam buku-buku pada saat itu dijelaskan dengan sangat hati-hati, teliti, dan benar berdasar teori Matematika. Inilah yang menyebabkan buku kurikulum 1975 dapat dikatakan bagus.

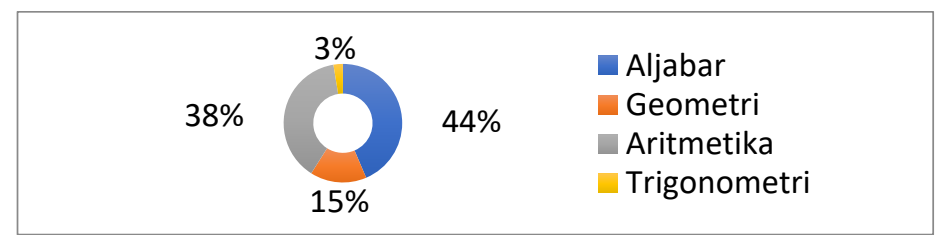

Gambar 1. Persentase Materi pada Buku Matematika SMP Kurikulum 1975 
Selanjutnya, penulis akan menjabarkan apa saja materi yang terdapat dalam buku Matematika SMP kurikulum 1975. Topik-topik dalam buku dikelompokkan menjadi empat yakni: Aljabar, Geometri, Aritmetika, dan Trigonometri. Pada semua buku, terdapat materi tentang Aljabar, Geometri dan Aritmetika. Di lain pihak, Trigonometri hanya dijumpai di buku 6. Jika melihat proporsi dari banyaknya bab untuk suatu topik pada buku (Gambar 1), maka kategori yang paling dominan adalah Aljabar yakni 44 persen, kemudian Aritmetika dengan 38 persen. Sementara itu, Geometri mencakup 15 persen dan Trigonometri hanya sebesar 3 persen.

Dalam menyajikan setiap bab, terdapat narasi, contoh soal dan jawabannya serta soal-soal latihan. Narasi dimulai dengan menjelaskan maksud atau definisi suatu konsep Matematika. Terdapat pula narasi yang dimulai dengan ilustrasi, atau analogi dalam kehidupan sehari-hari. Setelah itu, terdapat penjelasan tentang notasi matematika untuk suatu konsep Matematika. Contoh-contoh tergabung dalam narasi, yang berisi contoh suatu soal terkait topik yang dikerjakan. Terdapat beberapa istilah matematika yang saat ini tidak lazim digunakan. Diantaranya adalah pengacaraan linear, perkawanan satu-satu, dan teori kemungkinan yang lebih lazim dikenal saat ini dengan istilah program linier, korespondensi satu-satu, dan teori probabilitas. Terdapat pula ulasan sejarah yang dimasukkan ke dalam narasi. Salah satunya adalah pada pembahasan tentang panjang dengan penjelasan asal dari satuan meter. Karakteristik lain yang dapat dilihat pada buku kurikulum 1975 adalah mayoritas sub bab mencakup narasi yang sedikit dan banyak sekali latihan atau soal. Bahkan ada sub bab yang isinya hanya memuat soal-soal saja. Tentu saja ada pengecualian dimana ada sub bab yang narasinya lebih banyak.

Terdapat tiga macam latihan soal yang ada pada setiap buku: Latihan tanpa tanda, Latihan dengan label "A", dan Latihan dengan tanda "B". Latihan tanpa tanda dimaksudkan untuk dikerjakan oleh semua siswa. Sedangkan Latihan A dan B merupakan soal dengan bahan yang sama namun dengan tingkat kesulitan yang berbeda. Latihan A dimaksudkan agar lebih mudah dikerjakan daripada Latihan B. Lebih lanjut, Latihan B disarankan digunakan untuk kelas yang siswa-siswanya pandai Matematika dan untuk siswa yang gemar Matematika.

\subsection{Buku Matematika SMP Kurikulum 2013}

Terdapat enam buku yang telah ditelaah, karena jenjang SMP di Indonesia saat ini adalah tiga tahun dan tiap buku untuk satu semester. Berbeda dengan buku kurikulum 1975, penulis buku pada setiap kelas pada buku kurikulum 2013 berbeda. Selain itu, untuk setiap jenjang kelas memiliki penelaah buku yang berbeda. Perincian profil penulis dan penelaah buku kurikulum 2013 dicantumkan dalam buku dan hal ini tidak ada dalam buku kurikulum 1975. Berdasarkan profil yang ada pada setiap buku, para penulis dan penelaah buku terdiri atas guru dan dosen yang memiliki kecakapan dalam bidang Pendidikan Matematika dan Penulisan Buku. Mereka memiliki pengalaman baik mengajar di sekolah, atau di universitas, melakukan penelitian di bidang Pendidikan Matematika, maupun menyusun buku Matematika.

Proses penulisan buku dilakukan setelah Kementerian Pendidikan dan Kebudayaan menetapkan standar kompetensi dan silabus dan dilakukan oleh guru sekolah atau dosen di universitas (ACDP, 2017, hlm. 15). Setelah draf buku sudah jadi, hasilnya akan ditelaah oleh tim yang terdiri atas dosen-dosen yang kompeten yang kemudian dilanjutkan dengan persiapan 
penerbitan yang dilakukan oleh Pusat Kurikulum dan Perbukuan. Berdasarkan laporan ACDP dalam bukunya "Rapid Review of Curriculum 2013 Textbooks" dan buku-buku kurikulum 2013 yang penulis telaah, kami tidak menemukan informasi terkait uji coba buku.

Untuk melihat pengaruh buku-buku teks lain pada proses pengembangan buku kurikulum 2013, penulis melihat referensi dari setiap buku. Berdasarkan analisa yang telah dilakukan, penulis mengelompokkannya menjadi empat kategori: rujukan dari buku teks pelajaran matematika Indonesia (TI); buku teks pelajaran matematika Luar Negeri (TL); buku selain teks pelajaran Indonesia (BTI); dan buku selain teks pelajaran Luar Negeri (BTL). Hasil analisis menunjukkan bahwa secara keseluruhan, buku teks luar negeri mendominasi rujukan dari buku kurikulum 2013 (Gambar 2).

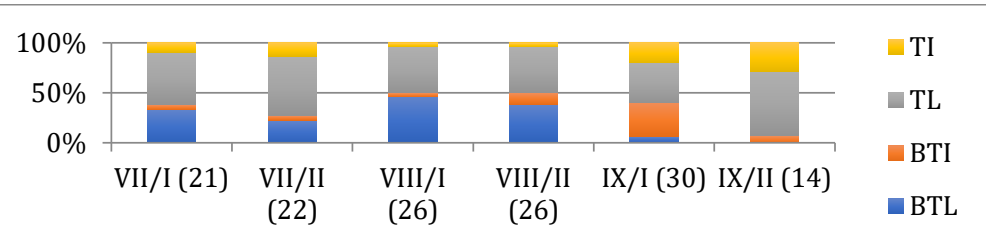

Gambar 2. Komposisi Buku Rujukan pada Buku Kurikulum 2013

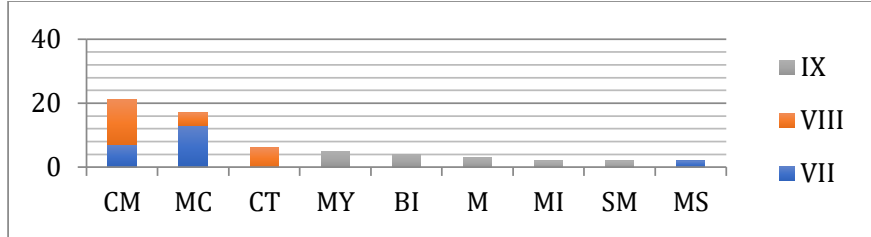

Gambar 3. Buku Rujukan Luar Negeri pada Buku Kurikulum 2013

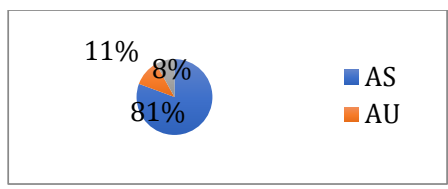

Gambar 4. Persentase Buku Rujukan Luar Negeri pada Buku Kurikulum 2013 Berdasarkan Negara Asal

Penulis mencoba menganalisis lebih jauh buku-buku teks dari luar negeri yang dijadikan rujukan buku matematika kurikulum 2013. Terdapat sembilan buku yang disadur oleh penulis buku matematika kurikulum 2013 (Gambar 3) yang berasal dari tiga negara yakni Amerika Serikat (AS), Australia (AU), dan Singapura (SG) (Gambar 4). Berdasarkan Gambar 5, tampak bahwa Amerika Serikat mendominasi rujukan buku Matematika Indonesia kurikulum 2013. Disusul oleh Australia dan Singapura

Berdasarkan Gambar 3, dua buku yang paling banyak dirujuk adalah Connected Mathematics (CM), kemudian Mathematics in Context (MC). CM merupakan buku produk dari sebuah proyek pengembangan buku yang dikembangakan oleh Michigan State University, Amerika Serikat (https://connectedmath.msu.edu/). Di lain pihak, MC merupakan buku yang dikembangkan oleh University of Wisconsin-Madison, Amerika Serikat berkolaborasi dengan the Freudenthal Institute, Belanda. Buku-buku yang lain adalah berikut: MathScape: Seeing and Thinking Mathematically (MS); California Math Triumphs (CT); Mathematics for Year 


\section{7, 8, and 9 (MY); Big Ideas Math Advanced (BI); Math Insights Secondary (MI); Signpost}

Mathematics (SM); dan Mathematics 1, 2, and 3 (M).

Meskipun berbeda dengan konten yang ada buku kurikulum 1975, banyak materi yang pada esensinya masih sama. Perbedaannya adalah pada buku kurikulum lama, secara jelas dibedakan mana materi yang termasuk Aljabar, Geometri, Trigonometri, dan Aritmetika, sedangkan hal ini tidak ditemukan di kurikulum 2013. Selain itu, pada kurikulum 2013, tidak terdapat materi Trigonometri. (sehingga variasi materi yang disematkan dalam buku kurikulum 2013 cenderung lebih sedikit dibandingkan kurikulum 1975).

Lebih lanjut, pada buku kurikulum 2013 terdapat usaha yang dilakukan oleh penulis untuk memasukkan unsur sejarah Matematika pada setiap bab. Penempatannya biasanya di awal pembahasan Bab. Misalnya, ulasan tentang Karl Pearson terdapat pada bab Statistika kelas VIII. Hal ini diapresiasi dan sesuai dengan perkembangan saat ini yang menyarankan integrasi sejarah matematika ke dalam pembelajaran (Wang dan Yang, 2015). Namun, pencantuman narasi sejarah di buku Matematika kurikulum 2013 terkesan bersumber dari Wikipedia dan tidak cocok dengan karakteristik siswa SMP (ACDP, 2017, hlm. 27).

Terdapat narasi-narasi yang dibangun dengan judul kegiatan atau aktivitas yang berisi cerita atau data dan ajakan kepada siswa untuk mengobservasi suatu permasalahan. Hal ini sudah bagus, namun, seperti yang diungkapkan oleh ACDP (2017, hlm. 27) bahwa "Even what was called an 'activity' was restricted and did not really qualify for that epithet." Contoh soal yang dikerjakan pada buku Kurikulum 2013 sangat banyak jika dibandingkan dengan yang ada di buku kurikulum 1975. Contoh ini sangat baik apalagi karena ia mencakup berbagai macam tipe soal termasuk aplikasi dari suatu konsep matematika. Soal-soal yang ditampilkan pada buku kurikulum 2013 juga sangat bervariasi jenisnya. Terdapat beberapa soal yang diambil dari TIMMS maupun PISA. Hal ini sesuai dengan kata pengantar pada buku yang menyatakan bahwa penyusunan buku salah satunya disesuaikan dengan standar internasional termasuk TIMMS dan PISA. Berbeda dengan kurikulum 1975, porsi soal yang ada di setiap bab pada buku kurikulum 2013 lebih kecil dibandingkan dengan narasi yang lain. Ada beberapa bagian lain dari setiap bab seperti kegiatan, peta konsep, sejarah, dan contoh soal serta jawabannya.

\subsection{Kriteria Buku Matematika SMP yang Baik}

Salah satu perbedaan antara buku kurikulum 1975 dan 2013 adalah adanya aktivitas pembelajaran di buku matematika kurikulum 2013. Aktivitas yang diberikan baiknya melibatkan kegiatan bermatematika, misalnya menyelesaikan masalah berbasis konteks di dunia nyata. Wijaya et al (2015, hlm. 60) menyebutkan banyaknya buku matematika kelas 8 kurikulum 2013 tidak menyediakan soal-soal berbasis konteks yang tidak memerlukan aktivitas pemodelan matematika. Sehingga, ada baiknya jika buku matematika SMP memuat soal-soal yang relevan dan sesuai konteks di dunia nyata, bukan seolah-olah dibuat nyata.

Selain itu, Firdausi \& Jupri (2020, hlm. 3) menyebutkan bahwa buku matematika SMP dari Kemendikbud lebih tebal dibandingkan dua buku dari penerbit swasta. Salah satu hal yang mempengaruhinya adalah banyaknya halaman yang memuat narasi dalam buku tersebut. Penulisan buku matematika SMP baiknya lebih sederhana dan memuat ilustrasi-ilustrasi yang membantu siswa memahami konten matematika sehingga dapat mengurangi jumlah halaman. 
Buku matematika SMP ada baiknya juga menyediakan buku khusus untuk latihan soal sebagai sumber pendukung belajar siswa (Danişman, 2019, hlm. 66). Hal ini juga mengingat bahwa soal-soal yang diberikan dalam buku matematika SMP ditempatkan setelah penjelasan yang akan mengurangi kesempatan siswa untuk mengembangkan kemampuan mereka sendiri (Wijaya et al, 2015, hlm. 60). Sehingga jika pemerintah menambahkan buku latihan soal sebagai sumber belajar, siswa akan memperoleh banyak kesempatan untuk belajar dan mengembangkan kemampuan matematika mereka.

Melibatkan penggunaan teknologi dalam memahami materi yang dimuat dalam buku matematika SMP memberikan manfaat lebih banyak kepada siswa. Hal ini tidak hanya membiasakan siswa memanfaatkan teknologi, namun juga memberikan pengaruh positif terhadap hasil belajar mereka (Drijvers et al, 2016, hlm. 3). Penambahan fitur teknologi dalam buku teks juga menjadi hal menarik bagi siswa sehingga bisa menjadi menambah nilai sebagai kriteria buku matematika SMP yang baik.

\subsection{Apa Saja yang Dapat Diperbaiki?}

Pertama, pemanfaatan versi digital dari buku Matematika SMP seharusnya dapat terus dikembangkan karena jika diperhatikan lagi, versi buku yang saat ini di Indonesia masih termasuk generasi pertama dari buku digital (O’Halloran, Beezer, \& Farmer, 2018). Pengembangan buku baru ini dapat dimulai dengan mencantumkan tautan pembelajaran terkait dan memberikan ilustrasi dinamis seperti video atau animasi grafik dalam GeoGebra atau Desmos. Tahapan selanjutnya adalah pemanfaatan Artificial Intelegency (AI) untuk dapat memprediksi kemampuan siswa, kelemahan siswa dan kelebihan siswa pada suatu topik. Dengan memanfaat AI penyusun buku digital ini mampu menyesuaikan desain materi seperti apa yang tepat untuk seorang siswa.

Tentu saja hal ini tidak mudah untuk dipraktikkan karena pada saat yang sama Indonesia yang masih memiliki banyak kekurangan dalam hal sarana prasarana terkait internet dan komputer utamanya yang menyangkut pendidikan. Untuk memanfaatkan buku digital harus ada sarana prasaran yang mendukung. Paling tidak kita tidak boleh tertinggal dari negara-negara yang sudah melesat jauh meninggalkan kita. Misalnya, Kanada sudah memanfaatkan penggunaan tablet untuk pembelajaran geometri pada bangku SD (Chorney \& Sinclair, 2018). Perancis juga sudah memulai proyek pembuatan buku elektronik (Pepin, Choppin, Ruthven, \& Sinclair, 2017, hlm. 653). Selain itu, Amerika Serikat memiliki University of Chicago School Mathematics Project (UCSMP) yang sudah beberapa tahun mengembangkan buku teks pelajaran matematika versi elektronik (Usisikin, 2018).

Kedua, proses pengembangan buku seharusnya melalui masa uji coba yang matang. Hal ini penting karena Indonesia merupakan negara yang sangat beragam, terutama dari segi sosial, kultural, dan ekonomi yang tentunya mempengaruhi sektor pendidikan. Di masa yang akan datang seharusnya Indonesia harus mengujicobakan di beberapa daerah dengan variasi kondisi sosial, kultural dan ekonomi. Selain itu, harus ada rencana jangka panjang ataupun berkelanjutan untuk pengembangan buku karena adanya uji coba ini dan yang tentunya membutuhkan masa perbaikan. Salah satu negara yang sudah cukup berhasil dalam 
menerapkan pengembangan buku dengan jangka waktu yang lama adalah Tiongkok (Xu, 2013).

Keempat, hal lain yang esensial dari sebuah buku adalah ilustrasi. Terdapat ilustrasi pada buku Kurikulum 2013 yang terlihat dibuat-buat. Misalnya, pada buku SMP kelas VII semester I, terdapat ilustrasi yang memperlihatkan sebuah resep dokter yang dibuat sendiri dengan nama samaran, padahal sangat mudah jika kita menginginkan data asli. Jika memang bisa memberikan ilustrasi asli dari kehidupan nyata seharusnya tidak perlu membuat ilustrasi yang tidak asli.

Kelima, penggunaan data nyata merupakan salah satu elemen esensial dari suatu buku matematika. Isu tidak menggunakan data nyata juga salah satunya terlihat pada sajian konsep statistika di buku kelas VIII semester II. Hal ini penting untuk diperhatikan karena, misalnya, dalam statistika sangat dianjurkan untuk menggunakan data yang nyata, yakni informasi nyata dari permasalahan nyata yang terjadi (Hulsizer \& Woolf 2009). Kontradiksi dengan anjuran tersebut, hampir semua data yang disajikan pada Bab Statistika tidak diambil dari sumber data yang riil. Padahal, jika ingin mencari data semacam ini sangat mudah, misalnya dengan merujuk situs web resmi Kementerian Keuangan yang menyajikan begitu banyak sajian data dengan berbagai macam diagram baik diagram garis, diagram batang, diagram lingkaran, maupun tabel.

\section{Kesimpulan dan Saran}

Berdasarkan hasil dari analisis buku yang dilakukan dalam penelitian ini, ditemukan bahwa jumlah buku matematika pada kurikulum 1975 dan 2013 tidak memiliki perbedaan, yaitu 6 buku dengan masing-masing buku digunakan untuk satu semester. Temuan lainnya adalah nama penyusun dan penelaah buku di buku teks kurikulum 1975 disebutkan. Sedangkan di dalam kurikulum 2013, tidak hanya nama penulis dan penelaah yang disebutkan, melainkan juga profil penulis dan penelaah dilampirkan dalam buku. Buku teks matematika kurikulum 1975 merupakan saduran dari buku yang disusun oleh perkumpulan ahli matematika Skotlandia. Sedangkan buku matematika kurikulum 2013 dominan merujuk negara Amerika Serikat, lalu disusul oleh Australia dan Singapura. Struktur dalam buku matematika 1975 dan 2013 hampir sama, yaitu: narasi, contoh soal, lalu latihan soal. Narasi dalam buku matematika 1975 cenderung lebih sedikit dibandingkan latihan soal. Buku matematika 2013 memberikan materi matematika yang dimuat lebih sedikit dibandingkan buku matematika 1975. Hasil analisis penelitian ini juga menunjukkan bahwa narasi yang dibangun dengan judul "kegiatan" atau "aktivitas" di dalam buku matematika kurikulum 2013 tidak benar-benar mencerminkan makna kegiatan itu sendiri. Ilustrasi pada buku tersebut juga terlihat dibuat-buat dan konsep statistika di dalam buku kelas VIII semester II kurikulum 2013 tidak menggunakan data yang nyata, hal ini cukup krusial untuk mengaitkan penggunaan matematika di kehidupan nyata. Namun, buku kurikulum 2013 termasuk pelopor dalam penyediaan buku bentuk digital.

Oleh karena itu, meskipun terdapat peningkatan terhadap buku kurikulum 2013, penelitian ini mengharapkan adanya perbaikan guna untuk peningkatan kualitas buku teks matematika nasional. Sebelum diterbitkan secara nasional, proses uji coba semestinya dilakukan pada siswa dan guru dengan latar belakang yang beragam. Hal ini akan meningkatkan kredibilitas 
buku teks nasional apakah mudah dipahami oleh seluruh siswa di Indonesia atau tidak, mengingat Indonesia begitu beragam secara sosial, kultural, dan ekonomi. Selain itu, pemanfaatan teknologi, selain kalkulator, semestinya dimanfaatkan dalam buku matematika, seperti GeoGebra. Pemerintah juga diharapkan dapat menyediakan sumber-sumber belajar yang mudah diakses oleh siswa dan ditautkan ke dalam buku. Ketebalan dan ukuran kertas yang digunakan buku teks juga perlu menjadi pertimbangan karena ini akan mempengaruhi kenyamanan siswa dan proses pertumbuhan mereka. Pengembangan buku dengan jangka berkelanjutan juga disarankan untuk masa perbaikan dan peningkatan kualitas di masa mendatang.

Penelitian selanjutnya dapat menelaah perkembangan buku Matematika di Indonesia dengan lebih rinci, misalnya dari Indonesia merdeka sampai kurikulum 2013. Artinya, yang diteliti adalah buku matematika kurikulum sebelum 1975, 1975, 1984, 1994, 2004, 2006, dan 2013. Namun, hal ini tentu saja tidak mudah, karena harus mencari buku-buku lama yang sangat sulit untuk dicari. Penelitian selanjutnya juga dapat menganalisis tipe-tipe soal berdasarkan tingkat kesulitan, kemampuan matematika tertentu, dan konten-konten matematika di dalamnya.

\section{Daftar Pustaka}

Analytical and Capacity Development Partnership (ACDP). (2017). Rapid review of curriculum 2013 and textbooks. Jakarta: ACDP

Beaton, A. E., Mullis, I. V. Martin, M. O., Gonzalez, E. J., Kelly, D. L., \& Smith, T. A. (1996). Mathematics achievement in the middle school years: IEA's third international mathematics and science study (TIMSS). Boston, MA: Center for the Study of Testing, Evaluation, and Educational Policy, Boston College.

Brodie, W. (1976). Scottish Mathematics Group. Dalam Chapman L.R. (Penyunting). The Process of Learning Mathematics. Hlm. 331-352. Oxford: Pergamon Press.

Charalambous, C. Y., Delaney, S., Hsu, H. Y., \& Mesa, V. (2010). A comparative analysis of the addition and subtraction of fractions in textbooks from three countries. Mathematical Thinking and Learning, 12(2), 117-151.

Chorney, S., \& Sinclair, N. (2018). Fingers-on Geometry: The Emergence of Symmetry in a Primary School Classroom with Multi-touch Dynamic Geometry. In Using Mobile Technologies in the Teaching and Learning of Mathematics (pp. 213-230). Springer, Cham.

Danışman, S. (2019). Examining mathematics teachers' use of curriculum and textbook. International Journal of Psychology and Educational Studies, , 6 (3), 61-72.

Drijvers, P., Ball, L., Barzel, B., Heid, M. K., Cao, Y., Maschietto, M. (2016). Uses of technology in lower secondary mathematics education: A concise topical survey. In ICME-13 topical surveys (pp. 1-34). New York, NY: Springer.

Fauzan, A. (2002). Applying Realistic Mathematics Education (RME) in teaching geometry in Indonesian primary schools. (Disertasi). University of Twente

Fan, L. (2013). Textbook research as scientific research: towards a common ground on issues and methods of research on mathematics textbooks. ZDM, 45(5), 765-777.

Firdausi, F. J. \& Jupri, A. (2020). Structure analysis of indonesian mathematics textbooks in the topic of relation and function for junior high school. Journal of Physics: Conference Series, 1521, pp. $1-7$.

Hadar, L.L. (2017). Opportunities to learn: Mathematics textbooks and students' achievements. Studies in Educational Evaluation, 55, 153-166.

Hadi, S. (2002). Effective teacher professional development for the implementation of realistic mathematics education in Indonesia. (Disertasi). University of Twente

Heck, R. H. (2004). Studying educational and social policy: Theoretical concepts and research methods. Routledge.

Holmes, P. (1975). Mathematics in School, 4(6), 32-32. Retrieved from http://www.jstor.org/stable/30211465 
Hulsizer, M. R., \& Woolf, L. M. (2009). A guide to teaching statistics: Innovations and best practices (Vol. 10). John Wiley \& Sons.

Kilpatrick, J. (2012). The new math as an international phenomenon. ZDM, 44(4), 563-571.

Mailizar, M., Alafaleq, M., \& Fan, L. (2014). A historical overview of mathematics curriculum reform and development in modern Indonesia. Teaching Innovations, 27(3), 58-68.

O’Halloran, K. L., Beezer, R. A., \& Farmer, D. W. (2018). A new generation of mathematics textbook research and development. ZDM, 50(5), 863-879.

Pepin, B., Choppin, J., Ruthven, K., \& Sinclair, N. (2017). Digital curriculum resources in mathematics education: Foundations for change. ZDM, 49(5), 645-661.

Sembiring, R. K., Hadi, S., \& Dolk, M. (2008). Reforming mathematics learning in Indonesian classrooms through RME. ZDM, 40(6), 927-939.

Sun, Y., Kulm, G., \& Capraro, M. M. (2009). Middle grade teachers' use of textbooks and their classroom instruction. Journal of Mathematics Education, 2(2), 20-37.

Thompson, D. R., Senk, S. L., \& Johnson, G. J. (2012). Opportunities to learn reasoning and proof in high school mathematics textbooks. Journal for Research in Mathematics Education, 43(3), 253-295.

Usiskin, Z. (2018). Electronic vs. paper textbook presentations of the various aspects of mathematics. ZDM, 50(5), 849-861.

Van Steenbrugge, H., \& Ryve, A. (2018). Developing a reform mathematics curriculum program in Sweden: relating international research and the local context. ZDM, 50(5), 801-812.

Valverde, G., Bianchi, L.,Wolfe, R., Schmidt,W. \& Houang, R. (2002). According to the book: Using TIMSS to investigate the translation of policy into practice through the world of textbooks. Dordrecht, The Netherlands: Kluwer.

Wang, J., \& Yang, Z. (2015). Study on Application of Mathematical History in Mathematics Textbooks in Mainland China. 3rd International Conference on Management, Education, Information and Control (MEICI 2015), hlm. 1575-1579.

Wijaya, A., Van den Heuvel-Panhuizen, M., \& Doorman, M. (2015). Opportunity-to-learn contextbased tasks provided by mathematics textbooks. Educational studies in Mathematics, 89, 41-65.

Williams, J. (1973). The Mathematical Gazette, 57(401), 229-230. doi:10.2307/3615599

$\mathrm{Xu}$, B. (2013). The development of school mathematics textbooks in China since 1950. ZDM, 45(5), $725-736$.

Zulkardi, Z. (2002). Developing a learning environment on realistic mathematics education for Indonesian student teachers. (Disertasi). University of Twente, Enschede. 